\title{
Evaluation of the Power Output Performance Improvement of a 2 MW Wind Turbine
}

\author{
Jui-Hung Liu ${ }^{{ }^{*}}$, and Jien-Chen Chen ${ }^{2}$, Wen-Jhen Lai ${ }^{3}$, Wei-Niam Su ${ }^{3}$ \\ ${ }^{1}$ Mechanical Engineering Dept., Southern Taiwan University of Science and Technology, Taiwan \\ ${ }^{2}$ Green Energy and Environment Lab., Industrial Technology Research Institute, Taiwan \\ ${ }^{3}$ Mechanical and System Engineering Program, Institute of Nuclear Energy Research, Taiwan
}

\begin{abstract}
This paper shows the possibility of the output improvement to a large wind turbine, so the operator can earn more and thus reduce the overall cost of energy. For a modern wind turbine certificated by IEC or DNV-GL guidelines, a 20 years design lifetime is a base line. However, the efficiency of the turbine will degrade after 8 or 9 years' operating. Some components, especially the turning blade, the efficiency may vary due to the surface condition change. Meanwhile, the controller technology may also have been improved after years. So, the turbine can regain its original output or even have a better output performance through some adjustments. In this paper, a $2 \mathrm{MW}$ wind turbine with different design and operating parameters like blade efficiency, wind direction alignment, high/low wind control strategy has been evaluated, then with the software DNV-GL BLADED simulation, to calculate the output differences and availability of the turbine. The result shown that a 3 5\% yield annually can be obtained for each improved parameter in a $9 \mathrm{~m} / \mathrm{s}$ mean wind speed situation.
\end{abstract}

\section{Introduction}

Wind energy has rapid growth recent years. According to GWEC's report [1], a world's total cumulative wind capacity is $486.8 \mathrm{GW}$ in 2016. And with annual installations in excess of $50 \mathrm{GW}$ which means over ten thousand of turbines have been installed all over the world each year. The forecast statistics also indicates a cumulative capacity growth more than $10 \%$ in the coming 5 years [1].

The market growth also shown the highly technology maturity compares to other renewable energies. With so many turbines installed all around the world in the recent 3 decades, the design standards for wind turbines have also been proved and updated for years. These design standards provide a basic and important guideline for the turbine developers, and manufacturers to choose, evaluate or design their turbines.

For a modern wind turbine certificated by IEC or DNV-GL guidelines, the design lifetime shall be at least 20 years [2, 3]. The guideline provides basic requirements for the turbine to operate safely and smoothly in its lifetime. And of course, after the installation of a wind turbine, the manufacturer will go through a fine tuning procedure to optimize the turbine's operation performance based on the design requirement and in-situ measurement. However, the efficiency of the turbine will degrade after 8 or 9 years' operation. Some components, especially the turning blade, the efficiency may vary due to the surface condition change.
Meanwhile, new controller methods may also been found during this period. So, the turbine may need an overall examine, retune, and controller re-design to improve the turbine's availability. As shown in Figure 1, two wind turbines' power curves have been plotted. These 2 turbines come from a same wind farm with 2 MW output capacities for each wind turbine. In the plot, the blue dotted line is the real output while the orange dotted line represents the design power curve. It can be clearly seen that the real curve of the turbine A has an obvious difference in the power output. The turbine B also showed a larger output offset in the below-rated wind speed region. This output difference results in a loss of the income from the electricity generation from the turbine.

This paper evaluates a $2 \mathrm{MW}$ wind turbine from a real operating wind farm with different design and operating parameters input like blade efficiency, wind direction alignment, high/low wind control strategy, then with the software DNV-GL BLADED's simulation, to calculate the output differences of the turbine to see how much annual output can be improved through these adjustments.

\section{System Description: Wind Turbine Model}

In this article, a generic $2 \mathrm{MW}$ turbine model was adopted as a reference to have a general evaluation on this topic. The basic specification of this turbine is listed 
in Table 1 with a nominal rotor speed $22.5 \mathrm{rpm}$, an optimum tip speed ratio 8 , and an optimal mode gain $98815 \mathrm{Nm} /(\mathrm{rad} / \mathrm{s})^{2}$ as its base line operation parameters. And the resulting design power curve is plotted in Figure 2. The turbine starts to generate the electricity at a cut-in wind speed of $3 \mathrm{~m} / \mathrm{s}$, power output to its rated at $12 \mathrm{~m} / \mathrm{s}$, then when the average wind speed is over $25 \mathrm{~m} / \mathrm{s}$, the turbine will stop automatically to prevent the dangerous operation under extreme wind condition.

From the power curve in Figure 2, the annual yield of the turbine can be calculated with the wind speed distribution probability (Figure 3) given the Weibull distribution shape factor 2 and a $98 \%$ availability. Table 2 is the calculation output for different annual average wind speed. For a $9 \mathrm{~m} / \mathrm{s}$ wind speed, it means more than 7 million $\mathrm{kWh}$ electricity can be generated annually. This number is an ideal calculation since the wind conditions, system control response, turbine faults, and maintenance all have influence to the final power output.

\section{Output Degradation Analyses}

As mentioned in Section 1, the power output may differ from the original design after years' operation. We can quantify the effects through the following analyses and calculations.

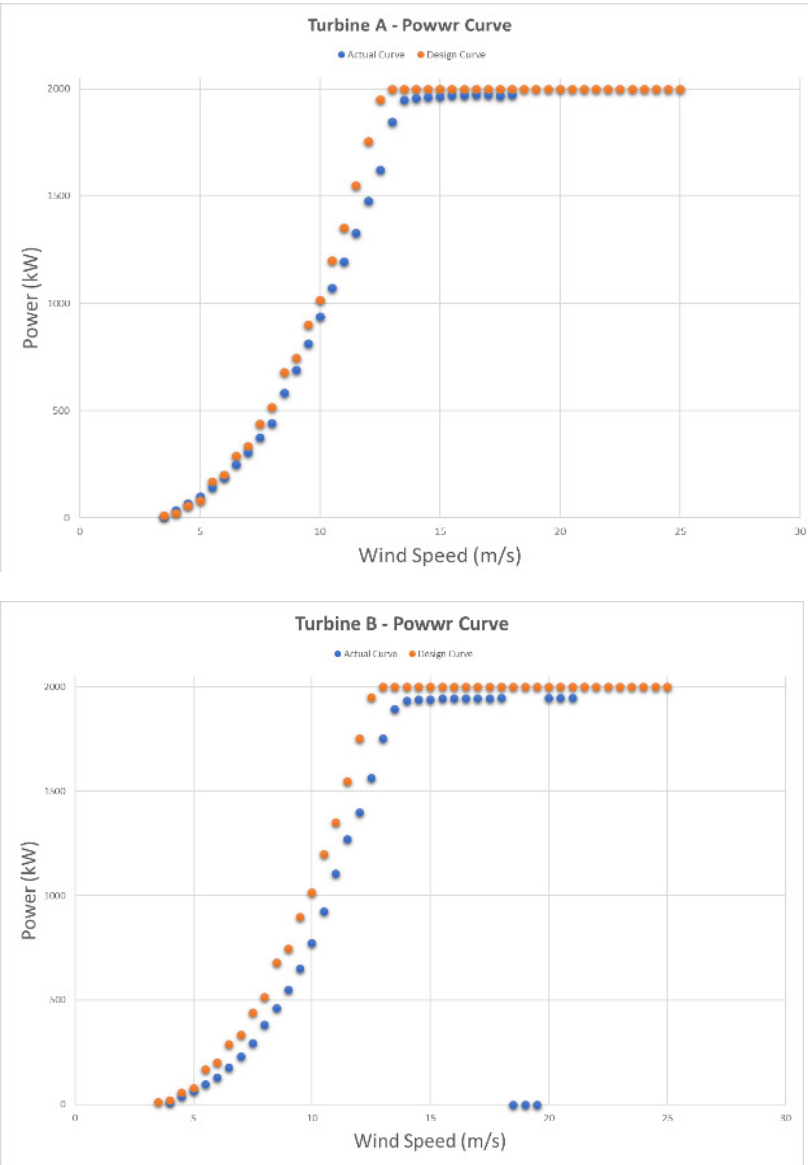

Fig. 1. Two turbines' actual power curve compare to the design one.
Table 1. Specification of the generic $2 \mathrm{MW}$ turbine.

\begin{aligned} \hline General & \\ \hline Rotor Diameter & $70.65 \mathrm{~m} \\ &$ Variable, nominal 22.5 \\ Rotor Speed & $\mathrm{rpm} \\$ Nominal Power & $2.0 \mathrm{MW} \\$ Rated Wind Speed & $12 \mathrm{~m} / \mathrm{s} \\$ Cut-in / Cut-out Wind Speed & $3 \sim 25 \mathrm{~m} / \mathrm{s} \\ & 8\left(\right.$ with Optimum $\mathrm{C}_{\mathrm{p}} \\$ Optimum Tip Sppd Ratio & $0.478) \\ & 98815 \mathrm{Nm} /(\mathrm{rad} / \mathrm{s})^{2} \\$ Optimum Mode Gain & $\sim 866 \mathrm{kNm} \\$ Generator Torque & \end{aligned}

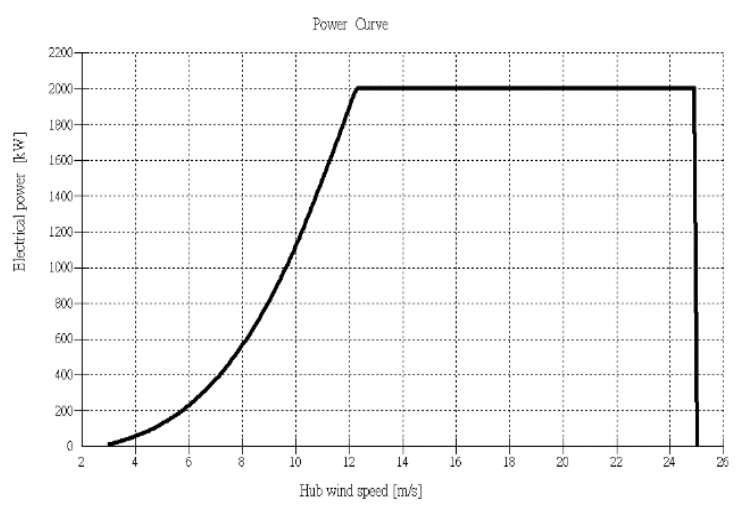

Fig. 2. Power of the generic $2 \mathrm{MW}$ turbine.

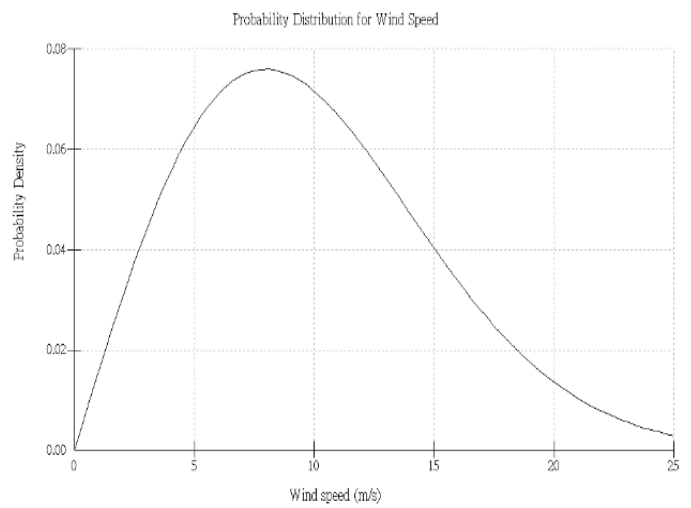

Fig. 3. Wind Distribution Probability.

Table 2. Annual Yield Calculation.

\begin{tabular}{cc}
\hline $\begin{array}{c}\text { Annual Mean Hub } \\
\text { Wind Speed (m/s) }\end{array}$ & Annual Energy Yield (kWh) \\
\hline 7 & $5.015 \mathrm{e}+06$ \\
8 & $6.461 \mathrm{e}+06$ \\
9 & $\mathbf{7 . 7 5 4 e + 0 6}$ \\
\hline
\end{tabular}




\subsection{Blade $C_{p}$ (Power $\underline{\text { Coefficient) }}$}

The turbine blades are rotating parts and have direct contact to the outside environment. So, its surface profile (aerofoil shape) may be changed by the dust's friction and salty water particle's erosion effects. Since the surface profile of the blade decides the energy conversion efficiency, that is the $\mathrm{C}_{\mathrm{p}}$ of the blade, the power output and control performance will be influenced, too. However, it's hard to measure exactly the change of the $\mathrm{C}_{\mathrm{p}}$. It can only be calculated and estimated from the actual power curve. Here, $\mathrm{C}_{\mathrm{p}}$ can be viewed as a parameter in the simulation, so the difference of the yield can be analysed. From Table 1, the original design optimum $\mathrm{C}_{\mathrm{p}}$ is 0.478 . Then three different $\mathrm{C}_{\mathrm{p}}$ values range from 0.365 to 0.478 were chosen to evaluate the performance differences as shown in Figure 4.

For the wind turbine control in the low wind speed region, $\mathrm{C}_{\mathrm{p}}$ and $\lambda$ (tip speed ratio) are two very important parameters to reach the MPPT (Maximum Power Point Tracking) strategy since the following formulas (1) (3) shown these two parameters should be kept to their optimum to have a MPPT curve.

$$
\begin{aligned}
& \text { Power }=\frac{1}{2} \rho A V^{3} C_{p}(\theta, \lambda) \\
& \lambda=\frac{\omega R}{V}
\end{aligned}
$$

where $\rho$ is the air density, $A$ is the rotor swept area, $V$ is the wind speed, $\theta$ is the blade pitch angle, and $\lambda$ is the tip speed ratio define by formula (2). Since the wind speed measure is not reliable from the anemometer behind the rotor, the formula (1) can be rewrite by replacing wind speed $\mathrm{V}$ with the relation of formula (2). Then the power output can be independent from the wind speed as shown in formula (3). In this mode, the blade angle $\theta$ and $\lambda$ should be both stay at its optimum, so the $\mathbf{C}_{\mathbf{p} \text {, opt }}$ and $\boldsymbol{\lambda}_{\text {opt }}$ is denoted in formula (3). Then, the formula can be simplified into a linear proportional relation in formula (4), where $K_{\text {opt }}$ is the product of all known parameters except rotational speed $W$.

$$
\begin{aligned}
& \text { Power }=\frac{1}{2} \rho \pi \mathrm{R}^{5} \mathrm{~W}^{3} \frac{\mathrm{C}_{\mathrm{p}, \mathrm{opt}}}{\lambda_{\mathrm{opt}}^{3}} \\
& \text { Power }=\mathrm{K}_{\mathrm{opt}} \mathrm{W}^{3}, \text { Torque }=\mathrm{K}_{\mathrm{opt}} \mathrm{W}^{2}
\end{aligned}
$$

The internal control algorithm will follow the formula (4) by measuring the rotor speed and then multiply with $\mathrm{K}_{\mathrm{opt}}$ to give the power or torque command to the system. With this optimum relation, the wind speed can be evaluated to match the power curve. When the real blade $\mathrm{C}_{\mathrm{p}}$ decreases, the power or torque command form formula (4) to reach the MPPT will no longer works. This means, for a same rotor speed, it represents a higher wind speed than the ideal one. The power output from formula (4) will thus be degraded. It needs a higher wind speed to reach the same power. This results in the power curve offset as shown in figure 5(a). And figure $5(\mathrm{~b})$ is a zoom in at wind speed from $6 \sim 11 \mathrm{~m} / \mathrm{s}$ to see more clear the differences. For the worst case, the black curve with $C_{p} 0.365$, the rated wind speed will be moved to $13 \mathrm{~m} / \mathrm{s}$. And the annual yields were calculated in table 3 according to different average wind speed. It's about $\underline{4 \%}$ electricity loss due to a slightly $C_{p}$ change. An obvious loss over $10 \%$ can be seen in the last and the worst case, $\mathrm{C}_{\mathrm{p}}=0.365$. However, this is an extreme case just to show the influence of $\mathrm{C}_{\mathrm{p}}$ and is unlikely to happen with a normal operation.

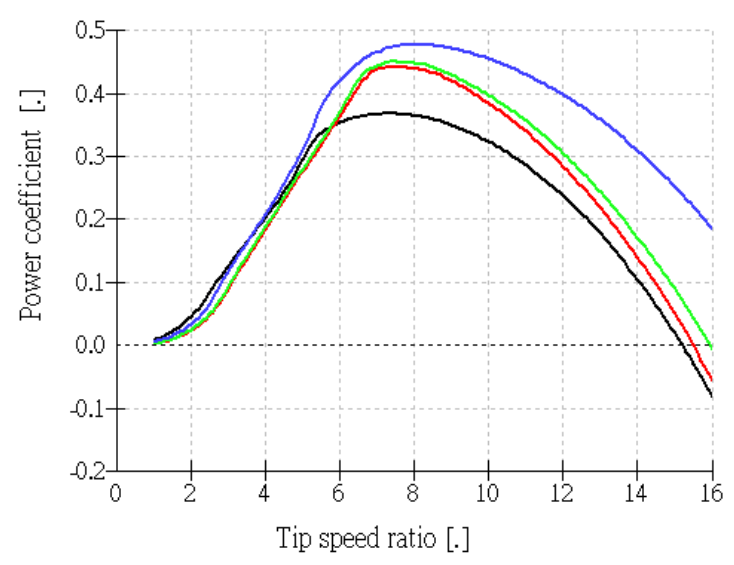

Fig. 4. Different $C_{p}$ curves with optimum from 0.478 to 0.36

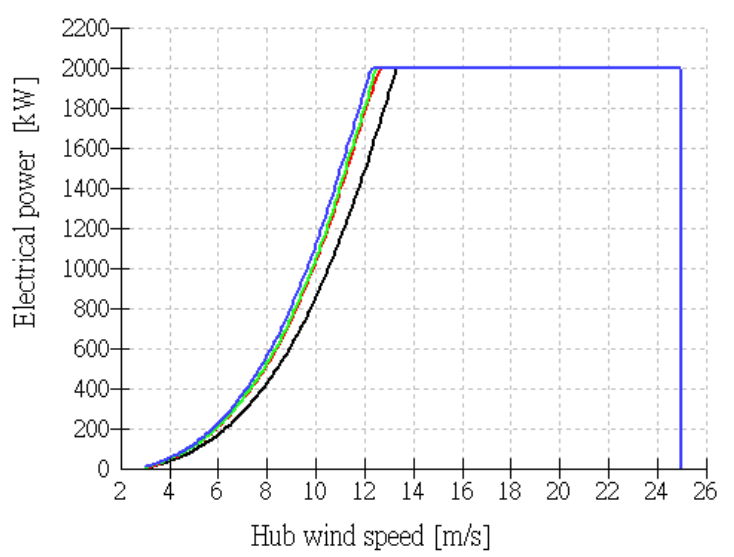

Fig. 5. (a)Power curves generated from different $C_{p}$

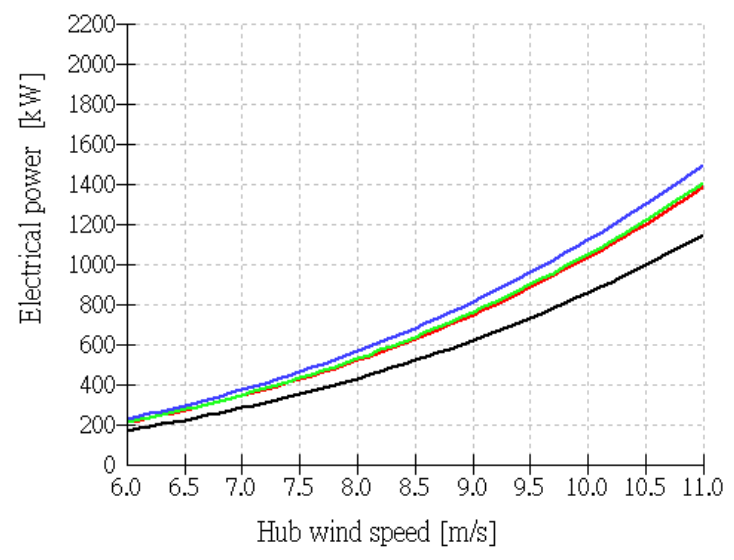

Fig. 5. (b)Zoom in at wind speed from $6 \sim 11 \mathrm{~m} / \mathrm{s}$ 


\subsection{Yaw Alignment Error}

The second parameter that may influence the power output performance is the yaw alignment error and the flow inclination. The ideal power curve assumes the wind comes from the upwind direction and directly exerts on the rotor swept surface without any yaw error and inclination. Although the turbine controller will turn the nacelle to align with the wind direction, it is not possible for such a big mass body (>100 tons) to do the alignment exactly and immediately since the wind direction is changing all the time. So the nacelle will not yawing continuously if the alignment error lies in the range about $+/-15$ degrees for this turbine. As a whole, this effect will be averaged for a loner time periods. Besides, this yaw alignment error can also come from the measurement of the cup anemometer. Since the yaw error is the difference between the nacelle position and the wind direction. This value can vary with time and need to be adjusted periodically. If not, this error can result in a large power curve offset as shown in figure 6. Its impact is even more than the $C_{p}$ variation. With a 10 degrees alignment error, the annual yield reveals a $\underline{\mathbf{5 \%}}$ more loss from the yaw error as listed in table 4 .

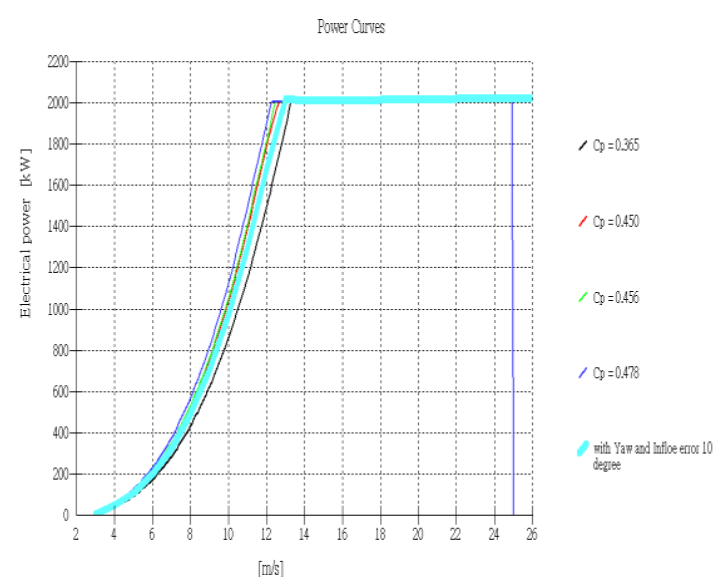

Fig. 6. Power curves comparison with Yaw misalignment and inflow inclination

\section{Retrofit Strategy in Controller}

From the analysis of two parameters that relates to the annual yield, it's possible for wind farm owner to check the operating power curve to see if the tuning is needed to bring back the power output. Besides these, what we can do to gain extra power is to increase rated power and extend the cutout wind speed [4]. If these strategies can be done carefully, the turbine's lifetime can also be extended as there also exist international standard especially for the lifetime extension of the wind turbines. [5 7].

\subsection{Rated Power Upgrade}

Assume that the generator's capacity can be overloaded within some small range, the power output will thus be increased if the operating parameters like rotor/stator temperatures can still lies within the safe values. The simulation bellows increased the generator output for $5 \%$ more, that is, $2100 \mathrm{~kW}$. Obviously, the power curve in Figure 7 has an offset after the rated wind speed. And the annual yield improvement is calculated and listed in Table 5. The difference is relative small especially when the mean wind speed is small than $8 \mathrm{~m} / \mathrm{s}$, only $2 \%$ increase in annual yield. For a 9 and $10 \mathrm{~m} / \mathrm{s}$ mean wind speed, $3 \%$ and $4 \%$ increase separately, these result is more effective and economical.

Table 3. Annual Yield Calculation of different $C_{p}$.

\begin{tabular}{ccccc}
\hline $\begin{array}{c}\text { Annual Mean Wind } \\
\text { Speed (m/s) }\end{array}$ & $\begin{array}{c}\text { Annual Yield (kWh) } \\
\mathbf{C}_{\mathbf{p}}=\mathbf{0 . 4 7 8}\end{array}$ & $\begin{array}{c}\text { Annual Yield (kWh) } \\
\mathbf{C}_{\mathbf{p}}=\mathbf{0 . 4 5 6}\end{array}$ & $\begin{array}{c}\text { Annual Yield (kWh) } \\
\mathbf{C}_{\mathbf{p}}=\mathbf{0 . 4 5 0}\end{array}$ & $\begin{array}{c}\text { Annual Yield (kWh) } \\
\mathbf{C}_{\mathbf{p}}=\mathbf{0 . 3 6 5}\end{array}$ \\
\hline 7 & $5.02 \mathrm{E}+06$ & $4.85 \mathrm{E}+06$ & $4.80 \mathrm{E}+06$ & $4.14 \mathrm{E}+06$ \\
8 & $6.46 \mathrm{E}+06$ & $6.29 \mathrm{E}+06$ & $6.23 \mathrm{E}+06$ & $5.50 \mathrm{E}+06$ \\
9 & $7.75 \mathrm{E}+06$ & $7.58 \mathrm{E}+06$ & $7.53 \mathrm{E}+06$ & $6.77 \mathrm{E}+06$ \\
10 & $8.83 \mathrm{E}+06$ & $8.67 \mathrm{E}+06$ & $8.61 \mathrm{E}+06$ & $7.87 \mathrm{E}+06$ \\
\hline
\end{tabular}

Table 4. Annual Yield Calculation of different $C_{p}$ and yaw error.

\begin{tabular}{ccccc}
\hline $\begin{array}{c}\text { Annual Mean } \\
\text { Wind Speed (m/s) }\end{array}$ & $\begin{array}{c}\text { Annual Yield (kWh) } \\
\mathbf{C p}=\mathbf{0 . 4 7 8}\end{array}$ & $\begin{array}{c}\text { Annual Yield (kWh) } \\
\mathbf{C p}=\mathbf{0 . 4 5 6}\end{array}$ & $\begin{array}{c}\text { Annual Yield (kWh) } \\
\mathbf{C p}=\mathbf{0 . 4 5 0}\end{array}$ & $\begin{array}{c}\text { Annual Yield (kWh) } \\
\text { with Yaw Error }\end{array}$ \\
\hline 7 & $5.02 \mathrm{E}+06$ & $4.85 \mathrm{E}+06$ & $4.80 \mathrm{E}+06$ & $\mathbf{4 . 5 7 E}+\mathbf{0 6}$ \\
8 & $6.46 \mathrm{E}+06$ & $6.29 \mathrm{E}+06$ & $6.23 \mathrm{E}+06$ & $\mathbf{5 . 9 9 E + 0 6}$ \\
9 & $7.75 \mathrm{E}+06$ & $7.58 \mathrm{E}+06$ & $7.53 \mathrm{E}+06$ & $\mathbf{7 . 2 8 E}+\mathbf{0 6}$ \\
10 & $8.83 \mathrm{E}+06$ & $8.67 \mathrm{E}+06$ & $8.61 \mathrm{E}+06$ & $\mathbf{8 . 3 6 E}+\mathbf{0 6}$ \\
\hline
\end{tabular}




\subsection{Cut-out wind speed Extended}

If we extend the normal cut-out wind speed from $25 \mathrm{~m} / \mathrm{s}$ to $28 \mathrm{~m} / \mathrm{s}$. The difference will not be so obvious since the probability of these wind speed range is relative small as we mentioned in Figure 3. In column 4 of Table 5, the extra energy obtain by this parameter is only $0.4 \%$ (about $34000 \mathrm{kWh}$ per year). This parameter need a site with higher Weibull shape factor to show its effectiveness.

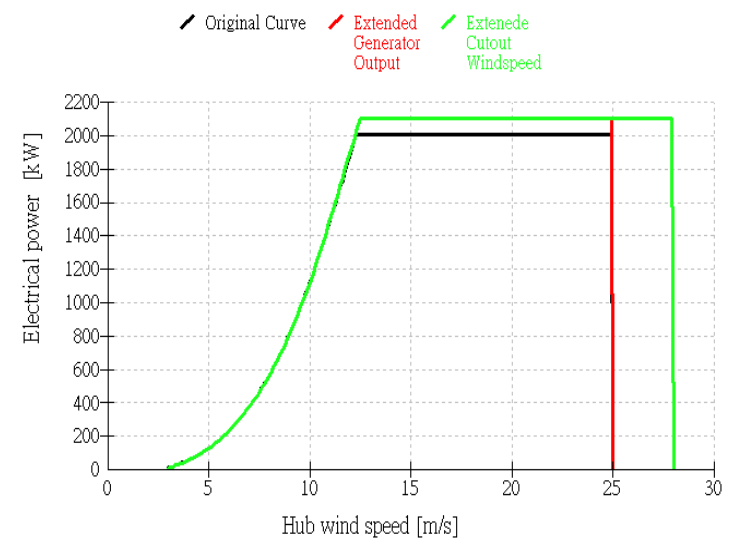

Fig. 7. Power curves comparison with Extended Generator Output and Cut-out Wind Speed

\section{Discussion}

In this article, investigations on various parameters that may influence the wind turbine output performance have been given. The blade's $C_{p}$, yawing misalignment, generator rated output upgrade, and cut-out wind speed extension are all possible and effective ways to bring back or increase the annual electricity yield, that is, much more income for the wind farm owners. From the simulation outcome, in general, a 3 5\% yield annually can be obtained for each improved parameter in a $9 \mathrm{~m} / \mathrm{s}$ mean wind speed situation. For the worst case that the turbine was downgraded due to long time operation and then upgraded by control strategy modification, a $12 \%$ increase may be achieved. This paper only addresses the steady state calculation. Much more dynamic simulations will be carried out in the future.

Acknowledgments: The financial support provided by Bureau of Energy and Institute of Nuclear Energy Research (Taiwan) are gratefully acknowledged.

Table 5. Annual Yield Calculation.

\begin{tabular}{ccccc}
\hline $\begin{array}{c}\text { Annual Mean } \\
\text { Wind Speed (m/s) }\end{array}$ & $\begin{array}{c}\text { Annual Yield (kWh) } \\
\mathbf{C p}=\mathbf{0 . 4 7 8}\end{array}$ & $\begin{array}{c}\text { Annual Yield (kWh) } \\
\text { Rated Power Upgrade }\end{array}$ & $\begin{array}{c}\text { Annual Yield (kWh) } \\
\text { Higher Cut-out Wind } \\
\text { Speed }\end{array}$ & $\begin{array}{c}\text { Percentage increased } \\
\mathbf{( \% )}\end{array}$ \\
\hline 7 & $5.02 \mathrm{E}+06$ & $5.09 \mathrm{E}+06$ & $\mathbf{5 . 0 9 E}+\mathbf{0 6}$ & $\mathbf{1 . 4 \%}$ \\
8 & $6.46 \mathrm{E}+06$ & $6.59 \mathrm{E}+06$ & $\mathbf{6 . 6 0 E}+\mathbf{0 6}$ & $\mathbf{2 . 2 \%}$ \\
9 & $7.76 \mathrm{E}+06$ & $7.95 \mathrm{E}+06$ & $\mathbf{7 . 9 8 E}+06$ & $\mathbf{3 . 0 \%}$ \\
10 & $8.83 \mathrm{E}+06$ & $9.09 \mathrm{E}+06$ & $\mathbf{9 . 1 8 8 + 0 6}$ & $\mathbf{4 . 0 \%}$ \\
\hline
\end{tabular}

\section{References}

1. GWEC, Global Wind Report - Annual Market Update 2016, GWEC, 2016.

2. DNV GL, Guideline for the Certification of Wind Turbines 2010 edition, DNV GL, 2010.

3. IEC, IEC 61400-1 wind turbines - part 1: Design Requirements (third edition), IEC, 2005.

4. Upgrading Vestas V47-660kW, Available online: http://www.mita-teknik.com/knowhow/turbine-retr ofit/retrofit-v47/ (accessed on 23rd July 2017).

5. New DNV GL standard and service specification for lifetime extension of wind turbines, Available online:

https://www.dnvgl.com/news/new-dnv-gl-standard -and-service-specification-for-lifetime-extension-o f-wind-turbines-61059
6. DNV-GL, Certification of lifetime extension of wind turbines(DNVGL-SE-0263), DNV-GL(, March 2016.

7. DNV-GL, Lifetime extension of wind turbines(DNVGL-ST-0262), DNV-GL, March 2016.

\footnotetext{
Corresponding author: dofliu@stust.edu.tw
} 